\title{
ANALISIS STRATEGI BERSAING RUMAH MAKAN (Studi Pada Rumah Makan Darisa Cafe Campus)
}

\author{
Akbar Riswandi \\ Harifuddin Thahir \\ Ira Nuriya Santi \\ Jurusan Manajemen, Fakultas Ekonomi, Universitas Tadulako \\ Email: akbarriswandi27@gmail.com
}

\begin{abstract}
The purpose of this study is 1) to find out the strengths and weaknesses of Darisa Cafe Campus Restaurant. 2) to find out the opportunities and threats of Restaurant Darisa Cafe Campus. 3) to find out the competitive strategy of Restaurant Darisa Cafe Campus. This research is a qualitative research with key informants are restaurant owners, restaurant managers and consumers. Data analysis techniques used are SWOT analysis (Strength, Weakness, Opportunities, Threats). Based on the results of the SWOT analysis, the result of the strength factor of Restaurant Darisa Cafe Campus has a score of 1.97 and strength factor of 1.09 so it has a total score of 3.06 while the external strategic factor analysis summary (EFAS). The result of the opportunity factor of Restaurant Darisa Cafe Campus has a score of 2.26 from the results of the SWOT diagram at Darisa Cafe Campus Restaurant is in quadrant 2 (Two ) are ST strategies (strengths and threats)
\end{abstract}

Keywords: Competition Strategi, Restaurant, SWOT.

\section{ABSTRAK}

Tujuan penelitian ini adalah 1). untuk mengetahui kekuatan dan kelemahan Rumah Makan Darisa Cafe Campus. 2) untuk mengetahui peluang dan ancaman Rumah Makan Darisa Cafe Campus. 3) untuk mengetahui strategi bersaing Rumah Makan Darisa Cafe Campus. Penelitian ini merupakan penelitian kualitatif dengan informan kuncinya adalah pemilik rumah makan, manajer rumah makan dan konsumen. Teknik analisis data yang digunakan adalah analisa SWOT (Strength, Weakness, Opportunities, Threats). Berdasarkan hasil analisis SWOT, dapat disimpulkan bahwa internal strategic factor analysis summary (IFAS), hasil faktor Kekuatan Rumah Makan Darisa Cafe Campus memiliki skor 1,97 dan faktor kekuatan, kelemahan memiliki skor 1,09 sehingga memiliki total skor 3,06 sedangkan external strategic factor analysis summary (EFAS), hasil faktor peluang Rumah Makan Darisa Cafe Campus memiliki skor 1,26 dan ancaman memiliki skor 2,10 sehingga memiliki total skor 3,36 dari hasil tersebut diagram SWOT pada Rumah Makan Darisa Cafe Campus berada pada posisi kuadran 2 (Dua) yaitu strategi ST (strengths dan threats.

Kata Kunci: Strategi Bersaing, Rumah Makan, SWOT.

\section{PENDAHULUAN}

Strategi bersaing adalah upaya yang dilakukan suatu perusahaan untuk memenangkan persaigan dalam mendapatkan konsumen yang lebih banyak dan tepat sasaran dengan cara pendekatan melalui pelayanan yang baik agar memberikan kepuasan kepada konsumen. Strategi bersaing yang baik meliputi tindakan-tindakan ofensif ataupum defensif guna menciptakan posisi yang lebih baik terhadap pesaing.

Rumah Makan Darisa Cafe Campus yang berada dijalan Untad 1 No. 009 Palu, Kecamatan Palu Timur, Kelurahan Tondo, Kota Palu, Sulawesi Tengah, merupakan rumah makan yang terbilang cukup baru berada di Kota Palu karna RM Darisa Cafe Campus berdiri sejak tahun 2015. Rumah Makan Darisa Cafe Campus menyediakan aneka hidangan seperti rumah makan pada umumnya. Konsep RM Darisa Cafe Campus didesain langsung oleh pemilik, manajer dan karyawan, target pasar Rumah Makan Darisa Cafe Campus mulai dari kalangan mahasiswa, mahasiswi, dosen, staf kampus dan masyarakat umum. Harga yang ditawarkan sangat menggugah selera pengunjung. 


\section{Riswandi, A.}

Keunggulan Rumah Makan Darisa Cafe Campus yaitu memiliki lingkungan yang bersih dan penghijuan sehingga pengunjung yang datang bisa merasakan kepuasan dengan lingkungannya, selain itu disini juga menyediakan free wifi, salah satu hal yang menarik dari Rumah Makan Darisa Cafe Campus ini yaitu memiliki gazebo yang berbentuk kerucut dan gazebo ini berkapasitas 8 orang sehingga sangat santai untuk berkumpul sama teman sambil makan. Alasan mengapa memilih RM Darisa Cafe Campus bersumber dari pengamatan yang dilakukan penulis objek penelitian karena secara fisik terlihat sangat menarik dan bagus kemudian harga makanan dan minuman yang dijual terbilang murah tapi pengunjungnya masih kurang jadi penulis ingin membantu untuk menerapkan strategi yang cocok. Adapun tujuan penelitian ini adalah untuk mengetahui kekuatan dan kelemahan; peluang dan ancaman; serta untuk mengetahui strategi bersaing Rumah Makan Darisa Cafe Campus.

\section{KAJIAN LITERATURE}

\section{Pengertian Strategi}

Menurut Rangkuti (2016:3), "strategi adalah alat untuk mencapai tujuan”. Menurut Jauch \& Glueck (1988:12), strategi adalah rencana yang disatukan, menyeluruh dan terpadu yang mengaitkan keunggulan strategi perusahaan dengan tantangan lingkungan dan yang dirancang untuk memastikan bahwa tujuan utama perusahaan dapat dicapai melalui pelaksanaan yang tepat oleh perusahaan. Daft (2010:249), mendefinisikan strategi (strategy) secara eksplisit, yaitu "rencana tindakan yang menerangkan tentang alokasi sumber daya serta berbagai aktivitas untuk menghadapi lingkungan, memperoleh keunggulan bersaing, dan mencapai tujuan perusahaan". Keunggulan bersaing (competitive advantege) adalah hal yang membedakan suatu perusahaan dari perushaan lain dan memberikan ciri khas bagi perusahaan untuk memenuhi kebutuhan pasar konsumen. Inti perumusan strategi adalah menentukan bagaimana perusahaan kita akan berbeda dengan perusahaan lain.

\section{Pengertian Manajemen Strategi}

Definisi manajemen strategi menurut David (2006:6), adalah sebagai seni dan ilmu untuk memformulasikan, mengimplementasi, dan mengevaluasi keputusan lintas fungsi yang memungkinkan organisasi dapat mencapai tujuannya. Tersirat dalam definisi, manajemen strategis berfokus pada mengintegrasikan manajemen, pemasaran, keuangan/akuntansi, produk/operasi, penelitian dan pengembangan, dan sistem informasi komputer untuk mencapai tujuan organisasi.

Menurut Jauch \& Glueck (1988:6), manajemen strategis adalah sejumlah keputusan dan tindakan yang mengarah pada penyususnan suatu strategi atau sejumlah strategi yang efektif untuk membantu mancapai sasaran perusahaan. Manajemen strategis (strategic management) didefinisikan Pearce dan Robinson (2014:3) sebagai suatu rangkaian keputusan dan tindakan yang menghasilkan formulasi dan implementasi rencana untuk mencapai tujuan perusahaan.

\section{Strategi Diversifikasi}

Kotler (2001:69), menyatakan konsep diversifikasi merupakan salah satu cara untuk meningkatkan kinerja bisnis yang ada dengan jalan mengidentifikasi peluang untuk menambah bisnis menarik yang tidak berkaitan dengan bisnis perusahaan saat ini. Menurut Tjiptono (2001:132) diversifikasi yaitu upaya mencari dan mengembangkan produk atau pasar yang baru, atau keduanya, dalam rangka mengejar pertumbuhan, peningkatan penjualan, profitabilitas dan fleksibilitas.

\section{Strategi Turn-Around}

Supardi dan Mastuti (2003:34), turn-around diambil ketika manajemen mengalami kegagalan dalam membesarkan perusahaan sehinggah prospek perusahaan menjadi tidak jelas dan mengalami krisis berkepanjangan, sehingga pemilik dan manajemen berusaha keras memutar arah organisasi. Menurut Davis dan Hofer (2002:54), terdapat dua macam strategi turn-around yang pernah dilakukan di negara-negara barat yaitu strategi operasi dan strategik. turn-around yang bersifat strategik 
difokuskan pada perubahan arah strategi perusahaan, positioning, aliansi, dan jenis produk, sedangankan turn-around yang bersifat operasional antara lain pengurangan karyawan dan retrenchment.

\section{Strategi Defensif}

Strategi defensif adalah jenis strategi dimana kondisi perusahaan sedang mengalami penurunan sehingga harus melakukan restrukturisasi melalui penghematan biaya dan aset untuk meningkatkan kembali penjualan dan laba yang sedang menurun. Menurut David (2002:17), strategi defensif yaitu strategi pengurangan kemungkinan beralihnya pelanggan ke pihak lain dengan langkah memperbaiki produk dan melindungi pangsa pasar dari para pesaing. Strategi ini dibagi lagi menjadi strategi pembentukan rintangan pengalihan dan strategi kepuasan pelanggan.

\section{Strategi Agresif}

Strategi agresif merupakan suatu pemikiran yang logis, analitis serta konseptualisasi hal-hal prioritas (dalam jangka panjang, pendek maupun mendesak), untuk dijadikan acuan dalam menetapkan langkah, tindakan, kiat, dan taktik yang harus dilakukan secara terpadu agar kegiatan terlaksana sesuai dengan tujuan, sasaran, dan hasil (output) yang harus dicapai berdasarkan kebijakan yang sudah ditetapkan sebelumnya. Strategi bertumbuh (Aggressive Strategy) difokuskan untuk memecahkan seluruh rintangan yang dihadapi dengan strategi yang sudah dirumuskan. perusahaan diharapkan memiliki kemampuan menerjemahkan strategi bertumbuh (Aggressive Strategy) pada tataran operasional, dimulai dengan mengukur investasi, aset, dan komponen lain yang diperlukan dalam pelaksanaan/implementasi strategi dalam memberikan pelayanan yang baik dibanding dengan pesaingnya.

\section{Pengertian Strategi Bersaing}

Menurut Rangkuti (2016: 153) Keberhasilan suatu strategi yang telah ditetapkan sangat ditentukan oleh seberapa besar tingkat kesesuaian strategi tersebut dengan perubahan lingkungan, pesaing, serta situasi organisasi faktor-faktor dalam merumuskan strategi dalam kondisi posisi persaingan yang kuat dan membangun kekuatan kompetitif.

Keunggulan kompetitif adalah strategi bersaing terhadap sesuatu yang dirancang untuk dieksploitasi oleh suatu organisasi. Bagaimana cara organisasi untuk mendapatkan keunggulan kompetitif yang berkelanjutan merupakan inti dari strategi bersaing. Pilihan strategi bersaing didasarkan pada keunggulan kompetitif yang dapat dikembangkan oleh organisasi. Bagaimana cara unit bisnis atau organisasi akan bersaing dalam suatu industri adalah pilihan dari strategi bersaing.

Keunggulan bersaing yang berkesinambungan terjadi pada saat perusahaan menerapkan suatu strategi pencipta nilai dan perusahaan pesaing tidak secara berkesinambungan menerapkannya, serta saat perusahaan lain tidak mampu meniru keunggulan bersaing tersebut. Kemudian Rangkuti mengemukakan bahwa keunggulan bersaing disebabkan oleh pilihan strategi yang dilakukan perusahaan untuk merebut peluang pasar.

\section{Strategi di Tingkat Korporat (Corporate Strategy)}

Menurut Andrews (1980: 18-19), strategi korporat adalah strategi yang disusun dalam suatu bisnis, ketika perusahaan akan bersaing dengan cara mengubah distinctive competence menjadi competitive advantage. Masalah yang cukup krusial dari strategi korporat ini adalah menentukan bisnis apa yang akan dikembangkan, bisnis apa yang ingin dipertahankan dan bisnis apa yang ingin dilepaskan. Keputusan untuk memasuki pasar baru dengan produk baru (diversifikasi), cara memasuki bisnis tersebut (misalnya, akusisi, pengembangan internal , joint venture), dan cara keluar bisnis (misalnya, spin-off, sell-off, likuidasi) merupakan cara-cara untuk dapat bersaing dan memperkuat keunggulan perusahaan, penerapan strategi korporat harus didasarkan kepada keinginan konsumen, baru setelah itu perusahaan membuat produk atau jasa yang sesuai dengan keinginan dan harapan konsumen. 


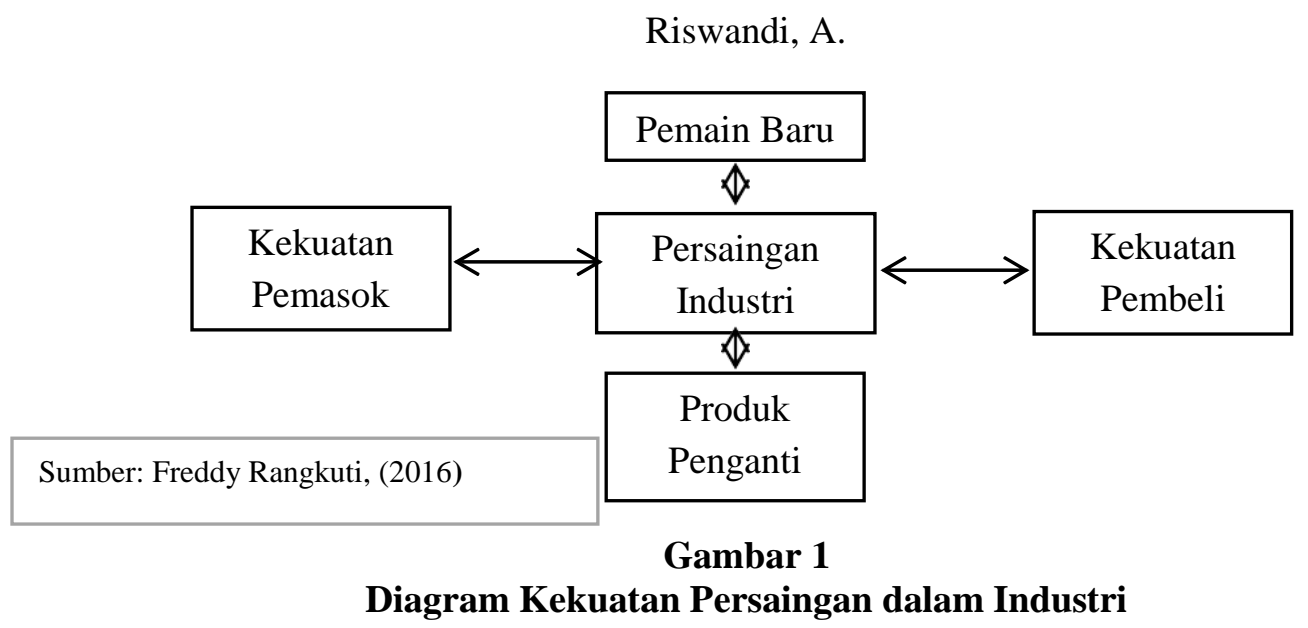

\section{Strategi Bersaing Generik Porter}

Pada pendekatan yang dikemukakan Porter, terdapat dua faktor yang diperhitungkan dalam menciptakan strategi bersaing yang tepat. Pertama, didasarkan pada keunggulan kompetitif organisasi. Menurut Porter, keunggulan kompetitif hanya akan diperoleh lewat salah satu dari dua sumber: bisa dari keunggulan menciptakan biaya yang rendah (cost leadership), atau dari kemampuan organisasi untuk menjadi berbeda (diferentiation) dibandingkan para pesaingnya. Faktor kedua dalam pendekatan ini adalah cakupan produk-pasar (competitive scope) dimana organisasi saling bersaing satu sama lain dalam pasar yang luas dan sempit.

\section{Analisis Swot}

Analisis SWOT adalah metode perencanaan strategis yang digunakan untuk mengevaluasi kekuatan (strengths), kelemahan (weaknesses), peluang (opportunities), dan ancaman (threats) dalam suatu proyek atau suatu spekulasi bisnis. Menurut Rangkuti (2016:19), "Analisis SWOT adalah indentifikasi berbagai faktor secara sistematis untuk merumuskan strategi perusahaan. Analisis ini didasarkan pada logika yang dapat memaksimalkan kekuatan (Strengths) dan peluang (Opportunities), namun secara bersamaan dapat meminimalkan kelemahan (weaknesses) dan anacaman (Threats)".

Pearce dan Robinson (2014:156), analisis SWOT merupakan teknik historis yang terkenal dimana para manejer menciptakan gambaran umum secara cepat mengenai situasi strategis perusahaan. Sutojo dan Kleinsteuber (2002:8), bahwa Analisis SWOT adalah menentukan tujuan usaha yang realistis, sesuai dengan kondisi perusahan dan oleh karenanya diharapkan lebih mudah tercapai.

\section{Matriks Swot}

Matriks SWOT adalah alat yang dipakai untuk menyusun faktor-faktor strategis perusahaan adalah matriks SWOT. Matriks ini dapat mengambarkan secara jelas bagaimana peluang dan ancaman eksternal yang dihadapi perusahaan dapat disesuaikan dengan kekuatan dan kelemahan yang dimilikinya. Matriks ini dapat menghasilkan 4 set kemungkinan alternatif strategis.

\section{Tabel 1 Matriks Faktor Internal dan Ekternal}

\begin{tabular}{|c|c|c|}
\hline $\begin{array}{l}\text { IFAS / } \\
\text { EFAS }\end{array}$ & $\begin{array}{l}\text { STRENGHT (S) } \\
\text { Tentukan 5-10 } \\
\text { Faktor Kekuatan Internal }\end{array}$ & $\begin{array}{l}\text { WEAKNESS }(\mathrm{W}) \\
\text { Tentukan 5-10 } \\
\text { Faktor Kelemahan Internal }\end{array}$ \\
\hline $\begin{array}{l}\text { OPPORTUNITY }(\mathrm{O}) \\
\text { Tentukan 5-10 } \\
\text { Faktor Peluang } \\
\text { Eksternal }\end{array}$ & $\begin{array}{l}\text { STRATEGI (SO) } \\
\text { Ciptakan strategi yang Menggunakan } \\
\text { kekuatan } \\
\text { untuk memanfaatkan peluang }\end{array}$ & $\begin{array}{l}\text { STRATEGI (WO) } \\
\text { Ciptakan strategi yang } \\
\text { meminimalkan kelemahan untuk } \\
\text { memanfaatkan peluang }\end{array}$ \\
\hline $\begin{array}{l}\text { THREATS }(\mathrm{T}) \\
\text { Tentukan 5-10 } \\
\text { Faktor Ancaman } \\
\text { Eksternal }\end{array}$ & $\begin{array}{l}\text { STARAEGI (ST) } \\
\text { Ciptakan strategi yang menggunakan } \\
\text { kekuatan untuk Mengatasi ancaman }\end{array}$ & $\begin{array}{l}\text { STRATEGI (WT) } \\
\text { Ciptakan strategi yang } \\
\text { meminimalkan kelemahan dan } \\
\text { menghindari ancaman }\end{array}$ \\
\hline
\end{tabular}




\section{Kerangka Pemikiran}

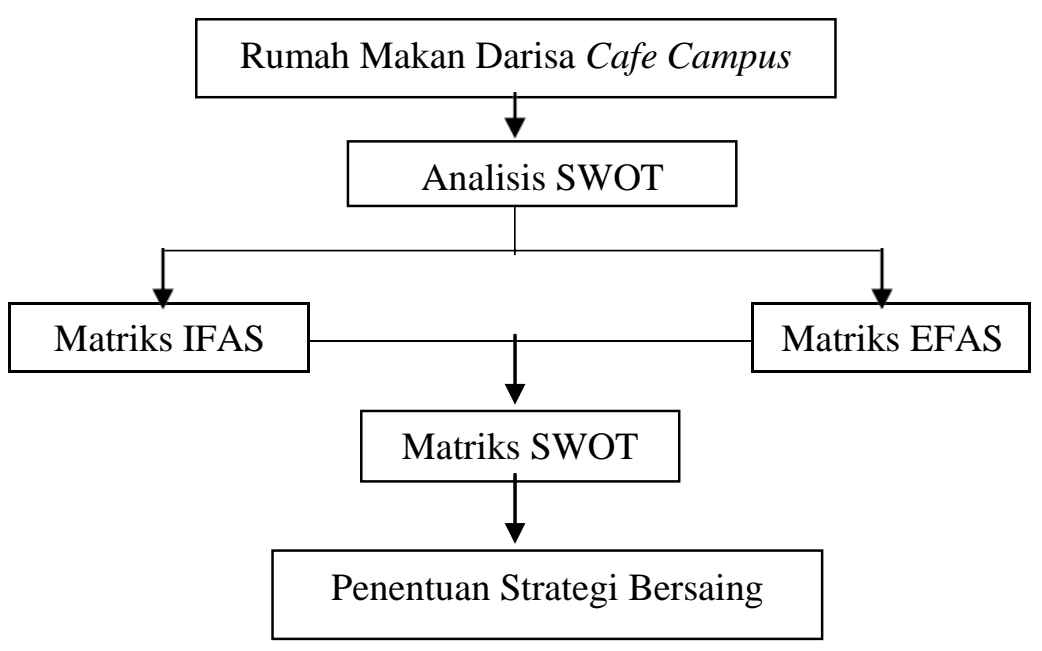

Gambar 2 Kerangka pemikir

\section{METODE PENELITIAN}

Penelitian ini dilakukan bersifat deskriftif dengan menggunakan pendekatan penelitian lapangan (field research) yakni penelitian yang dilakukan dengan langsung ke Rumah Makan Darisa Cafe Campus yang bertujuan untuk menganalisis strategi bersaing rumah makan tersebut. Teknik pengambilan dan pengumpulan data yang dilakukan dengan cara:

1. Penelitian pustaka (library research), melalui penelitian pustaka penulis juga mengumpulkan sumber informasi dari para ahli yang bersifat teoritis dan berhubungan dengan penelitian ini.

2. Penelitian lapangan (field research), yaitu dengan cara:

1) Observasi. Observasi yang didalamnya peneliti langsung turun ke lapangan untuk mengamati kondisi RM. Darisa Cafe Campus.

2) Wawancara. Wawancara adalah usaha untuk mengumpulkan data dengan melakukan wawancara berkaitan dengan visi dan misi Rumah Makan Darisa. Narasumber yang dipilih dalam penelitian ini yaitu sebanyak 3 (tiga) orang terdiri dari 1 (satu) orang pemilik Rumah Makan Darisa dan 1 (satu) orang Manejer Rumah Makan Darisa Cafe Campus dan 1 (satu) pengunjung.

3) Kuesioner. Kuesioner adalah pengumpulan data yang digunakan dengan cara membuat dan menyebarkan daftar penilaian dari pernyataan-pernyataan yang telah diajukan kepada narasumber.

4) Dokumentasi. Dokumentasi adalah teknik mengumpulkan data melalui bahan-bahan tertulis berupa struktur organisasi, serta dokumen-dokumen tentang pendapat dan teori yang berhubungan dengan masalah penelitian.

Metode analisis data menggunakan Analisis Swot. Posisi kuadran untuk analisis SWOT dapat dihitung menggunakan kombinasi rating dan bobot, dengan mengumpulkan informasi yang dilakukan melalui kuesioner kemudian dilakukan perhitungan pembobotan berdasarkan hasil pengisian kuesioner untuk kemudian dilakukan analisa lebih lanjut. Untuk membuat rencana strategi berdasarkan kapabilitas internal dan eksternal dilakukan dengan wawancara terkait pengisian kuesioner adalah sebagai berikut:

1. Memilih faktor-faktor internal dan eksternal yang telah dianalisa.

2. Pemberian peringkat atau rangking dari nilai 1 hingga 4 terhadap masing-masing faktor berdasarkan pada kondisi internal dan eksternal perusahaan tersebut. Cara penilaian adalah sebagai berikut: 
1) Nilai 1: Isu yang disampaikan sangat tidak relevan.

2) Nilai $2:$ Isu yang disampaikan tidak relevan.

3) Nilai $3:$ Isu yang disampaikan relevan.

4) Nilai 4 : Isu yang disampaikan sangat relevan

3. Model yang digunakan untuk menghitung bobot adalah sebagai berikut:

Tabel 2 Bobot SWOT

\begin{tabular}{|c|l|}
\hline STP & Sangat tidak penting jika isu sangat tidak mempengaruhi RM. Darisa Cafe Campus \\
\hline TP & Tidak penting jika isu tidak mempengaruhi RM.Darisa Cafe Campus \\
\hline R & Ragu-ragu jika isu tidak dapat dijustifikasi \\
\hline P & Penting jika isu mempengaruhi RM.Darisa Cafe Campus \\
\hline SP & Sangat penting jika isu sangat mempengaruhi RM.Darisa Cafe Campus \\
\hline
\end{tabular}

\section{HASIL DAN PEMBAHASAN}

\section{Kekuatan dan Kelemahan Rumah Makan Darisa Cafe Campus}

Proses analisis SWOT dilakukan untuk menguji sifat permintaan dan tekanan pihak eksternal, mengidentifikasi peluang dan kendala, sumber daya dan menilai kapasitas internal. Hasil Penilaian SWOT mengarahkan Rumah Makan Darisa Cafe Campus dalam pengembangan strategi untuk membangun kekuatan, mengatasi kelemahan, menangkal ancaman, dan mengeksploitasi peluang. Analisis SWOT memberikan informasi yang berguna untuk menyelaraskan sumber daya dan kemampuan dengan lingkungan yang kompetitif terhadap perusahaan. Model ini dapat digunakan untuk menentukan strategi dan berlaku juga untuk semua situasi membuat keputusan.

Hasil penelitian di lapangan menemukan deskripsi SWOT sebagai berikut:

1. Strength; penilaian terhadap Rumah Makan Darisa Cafe Campus untuk kekuatan internal dibandingkan dengan pesaing lainnya dapat diindikasikan sebagai berikut:

1) Menu yang disajikan memiliki cita rasa yang khas dan berbeda

Rumah Makan Darisa Cafe Campus memiliki cita rasa yang enak dan berbeda karna rempahrempah yang digunakan masih tradisional, kemudian diolah menjadi bumbu khas Rumah Makan Darisa Cafe Campus.

2) Fasilitas yang lengkap

Rumah Makan Darisa Cafe Campus memiliki beberapa fasilitas seperti wifi, musholla, toilet dan live karaoke dan dilengkapi beberapa gazebo.

3) Suasana Rumah Makan yang menarik dan nyaman

Suasana Rumah Makan Darisa Cafe Campus bagus karna konsep rumah makan tersebut penghijauan sehingga pengunjung merasa puas dan lingkungannya bersih dan adem.

4) Perusahaan Darisa sudah di kenal

Nama rumah makan Darisa sudah dikenal dikalangan masyarakat khususnya di Kota Palu yang berpusat di Jalan Setia Budi dan membuka tiga cabang diantaranya Jln DR. Abdulrahman Saleh, Jln Monginsidi dan di Jln Untad 1, maka orang-orang banyak yang mengenal, sehingga Rumah Makan Darisa berpeluang mendapatkan lebih banyak konsumen.

2. Weakness; adalah faktor internal mengenai kelemahan yang terkait dengan manajemen bisnis di Rumah Makan Darisa Cafe Campus dan merupakan lawan dari kekuatan perusahaan tersebut. Adapun faktor kelemahan adalah sebagai berikut:

1) Waktu penyajian yang cukup lama

Berdasarkan hasil penelitian lapangan di Rumah Makan Darisa Cafe Campus memiliki waktu penyajian yang cukup lama kisaran waktu 20 menit sampai 40 menit, sehingga menjadi salah satu kelemahan. 
2) Lahan parkir yang kurang luas

Rumah Makan Darisa Cafe Campus mempunyai dua tempat parkir, di depan dan di belakang, parkiran depan hanya berkapasitas kurang lebih 7 motor dan di belakang berkapasitas kurang lebih 3 mobil.

3) Kesulitan mendapatkan bahan baku.

Berdasarkan hasil observasi dan penelitian Rumah Makan Darisa Cafe Campus masih sulit mendapatkan bahan baku seperti daging dan rempah-rempah yang masih kurang.

4) Porsi makanan yang di sajikan kurang banyak

Hasil penelitian dilapangan bahwa menu yang disajikan Rumah Makan Darisa Cafe Campus terbilang sedikit seperti menu nasi goreng.

\section{Peluang dan Ancaman Rumah Makan Darisa Cafe Campus}

Analisis SWOT memberikan informasi yang berguna untuk Rumah Makan Darisa Cafe Campus dalam menyesuaikan sumber daya dan kemampuan dengan lingkungan eksternal yang kompetitif terhadap perusahaan. Model ini dapat digunakan untuk menentukan strategi dan berlaku juga untuk semua situasi membuat keputusan.

Hasil penelitian di lapangan menemukan deskripsi SWOT sebagai berikut:

1. Opportunities; merupakan peluang-peluang yang dapat dibuat atau diperoleh Rumah Makan Darisa Cafe Campus untuk tetap mengembangkan dan mempertahankan bisnis berdasarkan kemampuan.

Adapun peluang-peluang yang dapat diperoleh dan diciptakan adalah sebagai berikut:

1) Jumlah mahasiswa makin meningkat

Berdasarkan hasil penelitian dilapangan dan dapat kita lihat sendiri mahasiswa Universitas Tadulako tiap tahun semakin bertambah sehingga rumah makan semakin berpeluang untuk mendapatkan konsumen.

2) Berada diarea kampus Universitas Tadulako

Posisi Rumah Makan Darisa Cafe Campus cukup strategis karna berada diarea Universitas Tadulako tepatnya didekat pintu masuk samping dan berada di kompleks perumahan dosen (perdos)

3) Sering diadakan kegiatan kampus

Berdasarakan hasil penelitian dilapangan dengan sering diadakan kegiatan seperti seminar, besar, proposal dan skripsi Rumah Makan Darisa Cafe Campus berpeluang mendapatkan pesanan dari dalam kampus.

4) Kebutuhan jasa catering semakin meningkat

Salah satu peluang adalah dengan sering diadakannya kegiatan kampus seperti seminar, rapat, ujian proposal dan skripsi jumlah permintaan kebutuhan jasa catering Rumah Makan Darisa Cafe Campus semakin meningkat.

2. Threads; ancaman yang muncul bagi internal Rumah Makan Darisa Cafe Campus dan lingkungan industri. Adapun ancaman-ancaman yang ada adalah sebagai berikut:

1) Masuknya pendatang baru

Berdasarkan hasil observasi dan penelitian dilapangan bahwa disekitar area Universitas Tadulako terdapat banyak warung makan yang menjadi salah satu ancaman bagi Rumah Makan Darisa Cafe Campus diantaranya adalah Mas Fais, Mas Rusdi, Radja Penyet.

2) Ragam produk baru dihasilkan pesaing

Rumah Makan Darisa Cafe Campus harus mengembangkan produk yang dapat menghasilkan inovasi yang baru sehingga menjadi daya saing yang cukup kuat untuk mengatasi ancaman produk yang di hasilkan pesaing. maka Rumah Makan Darisa Cafe Campus mampu bertahan di tengah padatnya persaingan. 
3) Harga bahan baku tidak stabil

Harga bahan baku tidak stabil misalnya daging dan rempah- rempah, disebabkan karena yang kadang naik dan kadang turun harga, sehingga dapat menjadi salah satu ancaman yang berdampak pada kerugian bagi Rumah Makan Darisa Cafe Campus.

4) Konsumen berkurang jika tidak ada kegiatan kampus

Tidak ada kegiatan kampus seperti perkuliahaan merupakan Salah satu penyebab berkurangnya jumlah konsumen karena sebagian besar konsumen Rumah Makan Darisa Café Campus adalah mahasiswa, sehingga hal ini dapat menjadi salah satu ancaman yang dapat menyebabkan kerugian bagi Rumah Makan Darisa Cafe Campus.

\section{Analisis Faktor Internal dan Eksternal Menggunakan IFAS dan EFAS}

Tahap-tahap dalam menyusun tabel Internal Factor Analysis Summary (IFAS) dan Eksternal Factor Analysis Summary (EFAS) dengan menentukan indikator-indikator yang menjadi Strength, Weakness dan opportunities, threats Rumah Makan Darisa Cafe Campus, selanjutnya memberikan bobot masing-masing indikator dari hasil wawancara, hasil dari wawancara terdapat beberapa indikator, indikator internal terdapat delapan terbagi atas 4 kekuatan dan 4 kelemahan, dari 8 indikator akan diberi total 1,00 kemudian dibagi antara internal yang kuat akan diberi bobot yang tinggi sampai yang rendah yang diberikan oleh hasil wawancara, begitupun eksternal yang terdapat 8 indikator terdiri atas 4 peluang dan 4 ancaman. atau menggunakan peringkat dalam menentukan bobot dengan memberikan peringkat tinggi kepada indikator yang kuat hasil dari wawancara. Menghitung rating berdasarkan hasil penelitian yang diberikan oleh informan untuk masing-masing indikator dengan memberikan skala mulai dari 1 (sangat tidak relevan) sampai dengan 4 (sangat relevan). Nilai dari Strength dan Weakness selalu bertolak belakang, begitu juga dengan Opportunity dan Threat. Hasil analisis dari IFAS dan EFAS dapat dilihat pada tabel berikut:

Tabel 3 Matriks IFAS Rumah Makan Darisa Cafe Campus

\begin{tabular}{|c|c|c|c|}
\hline $\begin{array}{l}\text { Indikator-Indikator Strategis } \\
\text { Internal }\end{array}$ & Bobot & Rating & Skor \\
\hline 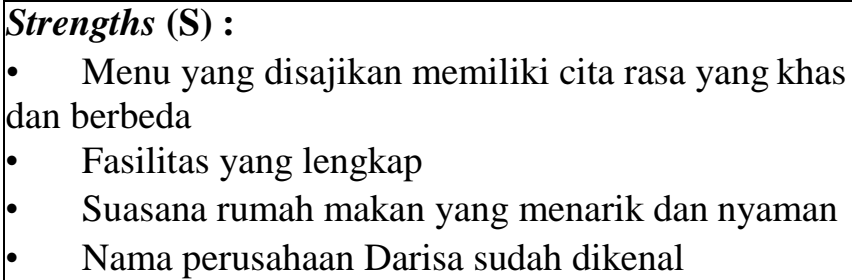 & $\begin{array}{l}0.13 \\
0.15 \\
0.11 \\
0.13\end{array}$ & $\begin{array}{l}4 \\
4 \\
3 \\
4\end{array}$ & $\begin{array}{l}0.52 \\
0.6 \\
0.33 \\
0,52\end{array}$ \\
\hline Sub Total & & & 1,97 \\
\hline 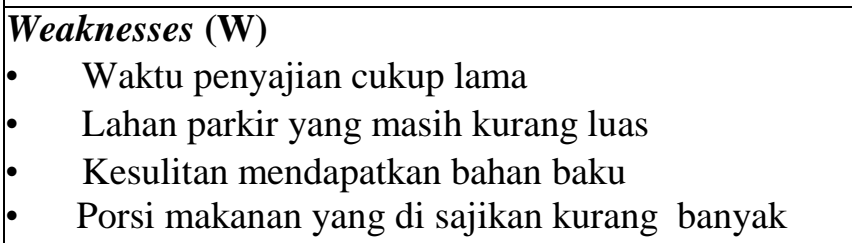 & $\begin{array}{l}0.07 \\
0.10 \\
0.20 \\
0.11\end{array}$ & $\begin{array}{l}1 \\
2 \\
3 \\
2\end{array}$ & $\begin{array}{c}0,07 \\
0,2 \\
0,6 \\
0,22\end{array}$ \\
\hline Sub Total & & & 1,09 \\
\hline
\end{tabular}

Sumber: Hasil penelitian yang diolah

Hasil analisis IFAS pada tabel 3, indikator kekuatan (Strength) mempunyai total nilai skor 1,97 sedangkan kelemahan (Weakness) mempunyai total nilai skor 1,09. Seperti halnya pada IFAS, maka pada indikator-indikator strategis eksternal EFAS juga dilakukan identifikasi yang hasilnya pada tabel berikut: 
Tabel 4 Matriks EFAS Rumah Makan Darisa Cafe Campus

\begin{tabular}{|l|c|c|c|}
\hline \multicolumn{1}{|c|}{$\begin{array}{c}\text { Indikator-Indikator Strategis } \\
\text { Eksternal }\end{array}$} & Bobot & Rating & Skor \\
\hline Opportunities (O) : & 0.13 & 3 & 0,39 \\
- Jumlah mahasiswa makin meningkat & 0.15 & 4 & 0,60 \\
- Berada di dekat Universitas Tadulako $\quad$ Sering diadakan kegiatan kampus & 0.10 & 2 & 0,20 \\
Kebutuhan jasa catering semakin meningkat & 0.07 & 1 & 0,07 \\
\hline Sub Total $\mathbf{0 . 4 5}$ & & & \\
\hline Threads (T) $\quad$ Masuknya pendatang baru & 0.15 & 4 & 0,60 \\
- Ragam produk baru dihasilkan pesaing & 0.15 & 4 & 0,60 \\
- Harga bahan baku tidak stabil & 0.10 & 3 & 0,30 \\
- Konsumen berkurang jika tidak ada kegiatan & 0.15 & 4 & 0,60 \\
\hline kampus & $\mathbf{1 . 2 6}$ \\
\hline Sub Total & $\mathbf{1 . 0 0}$ & & $\mathbf{3 , 3 6}$ \\
\hline
\end{tabular}

Sumber: Hasil penelitian yang diolah

Analisis tabel 4, menunjukkan bahwa untuk idikator peluang (Opportunities) nilai skornya 1,26 dan Indikator ancaman (Threats) 2,10, selanjutnya nilai total skor dari masing-masing faktor dapat dirinci:

- Indikator kekuatan (Strengths) : : $\quad$ :

- Indikator kelemahan (Weaknesses) : 1.09

- Indikator peluang (Opportunities) $\quad: 1.26$

- Indikator ancaman (Threats) : : 2,10

Maka diketahui nilai Strengths diatas nilai Weakness selisih (+) 0,88 dan nilai Opportunities dibawah nilai Threads selisih (-) 0,84. Hasil identifikasi indikator-indikator tersebut maka dapat digambarkan dalam Diagram SWOT, dapat dilihat pada gambar 3.

\section{PELUANG}

\section{$(1,26)$}

III

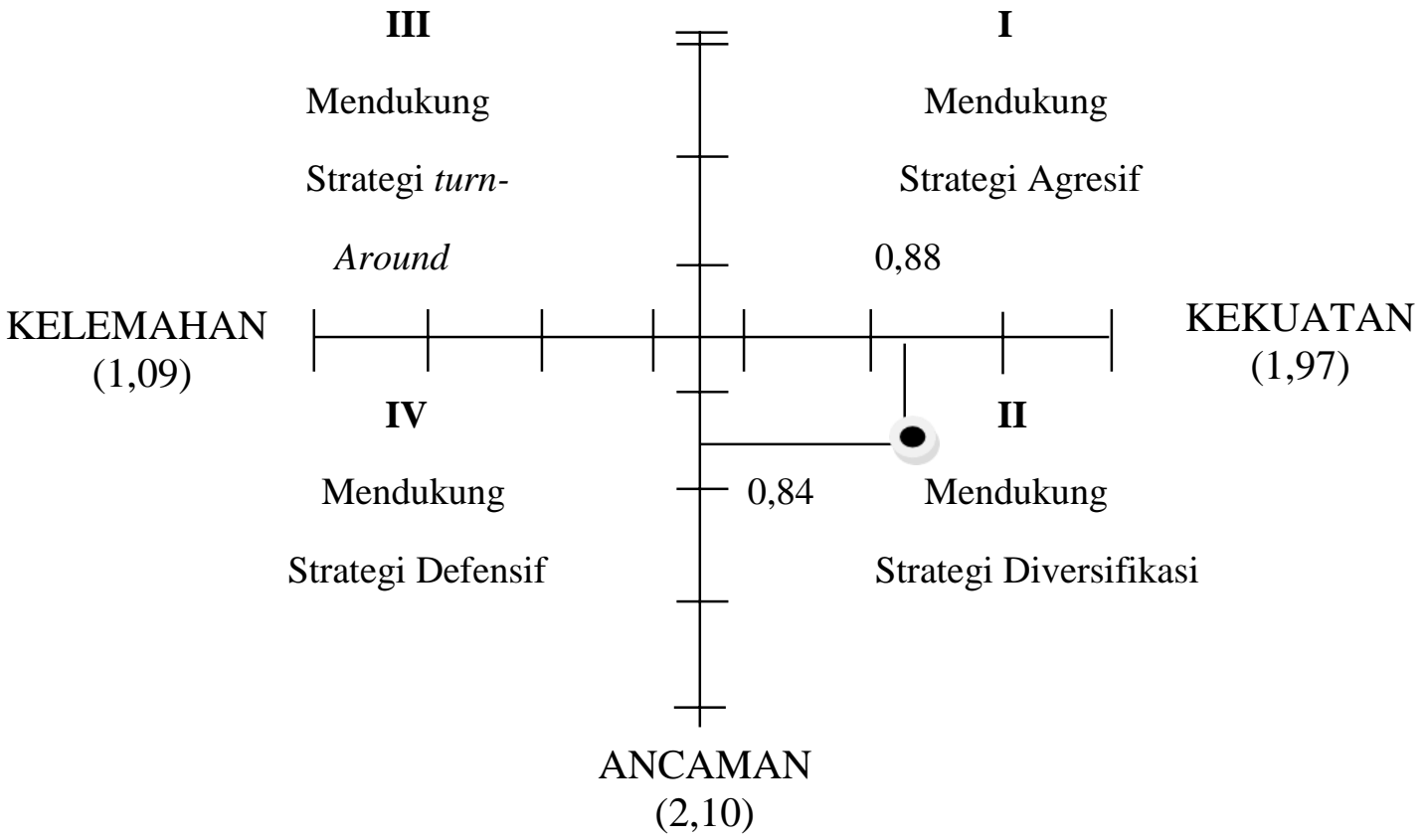

Gambar 3 Diagram SWOT 


\section{Riswandi, A.}

Berdasarkan nilai total masing-masing indikator selain digambarkan dalam diagram SWOT juga dapat digambarkan dalam rumusan matrik SWOT sebagai berikut:

Tabel 5 Rumusan Kombinasi Strategi Matriks SWOT

\begin{tabular}{|l|l|l|}
\hline EFAS & \multicolumn{1}{|c|}{ Strength $(\mathbf{S})$} & \multicolumn{1}{|c|}{ Weakness $(\mathbf{W})$} \\
\hline \multirow{3}{*}{ Opportunity (O) } & Strategi (SO) : & Strategi (WO) $:$ \\
& $=1,97+1,26$ & $=1,09+1,26$ \\
& $=3,23$ & 2.35 \\
\hline \multirow{3}{*}{ Threat $(\mathbf{T})$} & Strategi (ST) $:$ & Strategi (WT) $:$ \\
& $=1,97+2,10$ & $=1,09+2,10$ \\
& $=4,07$ & $=3,19$ \\
\hline
\end{tabular}

Sumber: Hasil penelitian diolah

\section{Matriks SWOT}

Berdasarkan analisis matriks IFAS dan EFAS pada tabel 3 dan tabel 4, telah disusun pula matriks SWOT untuk menganalisis rumusan alternatif strategi SO, WO, ST dan WT yang hasil analisisnya seperti pada tabel 6 .

Tabel 6 Matriks SWOT Rumah Makan Darisa Cafe Campus

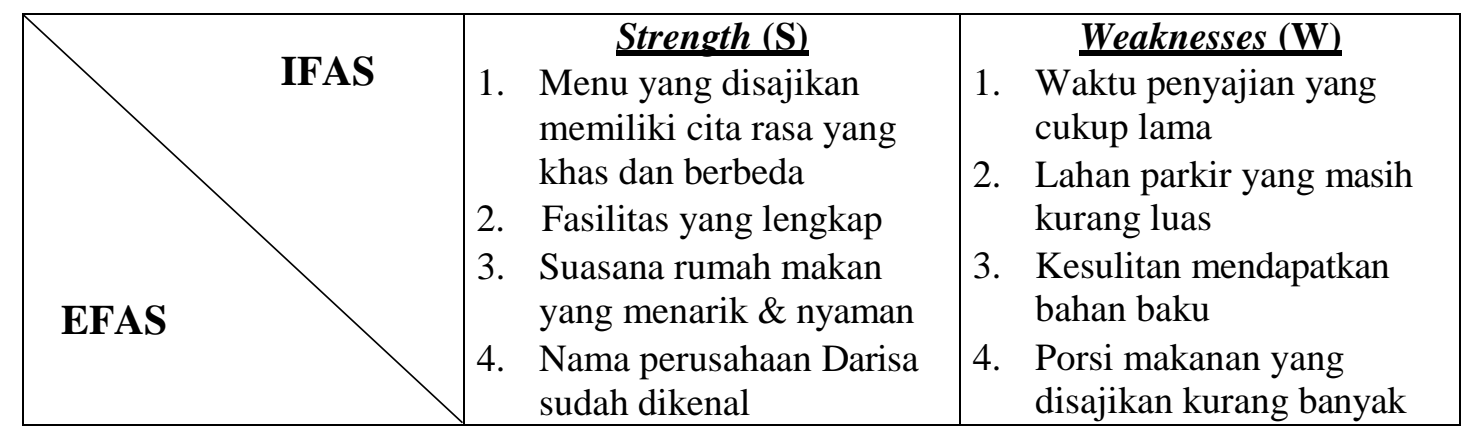

\section{Opportunities $(\mathrm{O})$}

1. Jumlah mahasiswa semakin bertambah

2. Berada di dekat kampus Universitas Tadulako

3. Sering diadakan kegiatan kampus

4. Kebutuhan jasa catering semakin meningkat.

\section{Threats (T)}

1. Ancaman masuknya pemain baru

2. Banyaknya produk pengganti yang dihasilkan pesaing

3. Harga bahan baku tidak stabil

4. Konsumen berkurang jika tidak ada kegiatan kampus.

\section{Strategi SO}

- Menjalin hubungan kerja sama dengan Universitas Tadulako untuk pemesanan nasi dos dalam kegiatan kampus.

(S1,S4,O1,O2,O3,O4)

- Membuka jam kerja dihari libur kampus

$(\mathrm{S} 2, \mathrm{~S} 3, \mathrm{~S} 4, \mathrm{O} 1, \mathrm{O} 2, \mathrm{O} 3)$

\section{Strategi WO}

- Membuat lahan parkir yang luas agar.

(W2,O1,O2,O3)

- Melakukan promosi produk, melalui cara paket menarik dan murah (W1,O1,O2,O3)

\section{Strategi WT}

- Menjalin kerja sama yang baik dengan pemasok dan menambah kuantitas pemasok

(S1,S2,S3,T1,T2,T3)
- Meningkatkan promosi produk unggulan tanpa melupakan produk produk yang belum dikenal luas dipasaran

$(\mathrm{S} 4, \mathrm{~T} 1, \mathrm{~T} 2, \mathrm{~T} 3, \mathrm{~T} 4)$

\section{(W3,T2,T3)}

- Tetap menjaga \& meningkatkan kualitas produk dalam bentuk nasi dos, prasmanan, dll (W4,T1,T2,T3) 


\section{Strategi Bersaing Berdasarkan Hasil Analisis SWOT}

Berdasarkan Gambar Diagram SWOT hasil dari evaluasi dan terpetakan pada kuadran ST (strenghts \& threaths) maka untuk selanjutnya strategi akan berfokus kepada strategi ST dimana strategi ST yang telah disebutkan pada tabel Matriks SWOT akan melakukan strategi menggunakan kekuatan untuk mengatasi ancaman yang dihadapi dengan cara strategi diversifikasi (produk/pasar) dengan program strategi sebagai berikut:

1. Mempercepat waktu Pelayanan

Rumah Makan Darisa Cafe Campus sudah memiliki kekuatan pada suasana tempat yang tidak dimiliki oleh para pesaing, suasana dan fasilitas Rumah Makan Darisa Cafe Campus membuat konsumen nyaman berlama-lama menikmati menu yang disajikan sehingga perlu dipertahankan untuk mengatasi pesaing-pesaing dari pendatang baru maupun yang sudah lama dalam industri rumah makan di area kampus serta perlu adanya peningkatan pada jenis pelayanan lainnya seperti mempercepatnya menu yang disajikan kepada konsumen agar konsumen puas.

2. Meningkatkan promosi produk unggulan tanpa melupakan produk-produk yang belum dikenal luas dipasaran

Rumah Makan Darisa Cafe Campus sudah terkenal cukup lama dengan adanya cabang-cabang lain yang berada dalam kota Palu diantaranya yaitu pusat Rumah Makan Darisa yang berada dijalan Setia Budi dan iklan di koran-koran lokal dan radio, akan tetapi promosi tersebut tidaklah cukup untuk menghadapi persaingan industri rumah makan yang ketat diarea salah satu kampus terbesar di kota Palu yaitu Universitas Tadulako, dapat kita lihat sendiri pertumbuhan rumah makan selalu meningkat disetiap area kampus didalam maupun diluar kampus, maka dari itu Rumah Makan Darisa Cafe Campus diwajibkan melakuan promosi dengan berbagai cara seperti: :

3. Pemberian harga yang kompetitif

4. Pemberian harga discount ke konsumen untuk yang merayakan ulang tahun di Rumah Makan Darisa Cafe Campus

5. Bekerja sama dengan jasa kurir online untuk melakukan pengantaran cathering pada setiap pemesanan mendadak

6. Melakukan promosi setiap hari di Sosial Media (Instagram, Facebook, Twitter, Youtube, dan lainlain)

7. Melakukan Delivery Order.

8. Memprioritaskan atau memperkuat menu spesial untuk mahasiswa dan menambah jumlah varian menu cemilan (Snack) yang harganya bersahabat dengan mahasiswa.

9. Untuk menu yang kurang bahan bakunya, strategi yang harus diterapkan ialah meningkatkan jumlah pemasok yang terpercaya dan mempercepat waktu pelayanan agar konsumen tidak menunggu lama.

10.Menjaga kebersihan rumah makan dan lingkungan.

\section{KESIMPULAN DAN SARAN}

\section{Kesimpulan}

Berdasarkan hasil pembahasan yang dikemukakan, maka dapat ditarik suatu kesimpulan yaitu:

1. Analisis SWOT, menunjukkan bahwa internal strategic factor analysis summary (IFAS), hasil faktor kekuatan Rumah Makan Darisa Cafe Campus memiliki skor 1,97 dan faktor kekuatan Kelemahan memiliki skor 1,09 sehingga memiliki total skor 3,06.

2. Analisis SWOT, menunjukkan bahwa external strategic factor analysis summary (EFAS), hasil faktor peluang Rumah Makan Darisa Cafe Campus memiliki skor 1,26 dan ancaman memiliki skor 2,10 sehingga memiliki total skor 3,36.

3. Berdasarkan hasil tersebut diagram SWOT pada Rumah Makan Darisa Cafe Campus berada pada posisi kuadran 2 (Dua) yaitu menggunakan strategi ST. 


\section{Saran}

1. Sebaiknya pemilik Rumah Makan Darisa Cafe Campus harus menganalisa setiap bulan tentang kekuatan, kelemahan, peluang dan ancaman dari Rumah Makan Darisa Cafe Campus, sehingga dapat mengetahui strategi yang tepat dalam mengatasi pesaing.

2. Diketahui dari Analisis SWOT, Strategi yang harus diterapkan Rumah Makan Darisa Cafe Campus adalah menggunakan kekuatan untuk mengatasi ancaman yang dihadapi dengan cara strategi diversifikasi.

3. Meningkatkan Pelayanan. Rumah Makan Darisa Cafe Campus sudah memiliki kekuatan pada suasana tempat yang tidak dimiliki oleh para pesaing, suasana Rumah Makan Darisa Cafe Campus membuat konsumen nyaman berlama-lama menikmati menu yang disajikan sehingga perlu dipertahankan untuk mengatasi pesaing-pesaing dari pendatang baru maupun yang sudah lama dalam industri rumah makan di area kampus serta perlu adanya peningkatan pada jenis pelayanan lainya seperti cepatnya menu yang disajikan kepada konsumen agar konsumen tidak bosan untuk kembali makan di Rumah Makan Darisa Cafe Campus.

4. Meningkatkan strategi promosi. Rumah Makan Darisa Cafe Campus sudah cukup terkenal cukup lama dengan adanya cabang-cabang lain yang berada dalam kota Palu diantaranya yaitu pusat Rumah Makan Darisa yang berada dijalan Setia Budi dan iklan di koran-koran lokal dan radio, akan tetapi promosi tersebut tidaklah cukup untuk menghadapi persaingan industri rumah makan yang ketat diarea salah satu kampus terbesar di kota Palu yaitu Universitas Tadulako, dapat kita lihat sendiri pertumbuhan rumah makan selalu meningkat disetiap area kampus didalam maupun diluar kampus, maka dari itu Rumah Makan Darisa Cafe Campus diwajibkan melakuan promosi dengan berbagai cara dengan menggunakan media sosial seperti instagram, facebook, youtube, twitter dan memberikan diskon.

5. Memperluas Lahan Parkir. Rumah Makan Darisa Cafe Campus memiliki tempat yang cukup strategis dan memiliki fasilitas yang lengkap seperti wifi, toilet dan musollah hal ini menjadi salah satu kekuatan yang belum tentu dimiliki oleh pesaing akan tetapi itu tidak cukup untuk menghadapi pesaing, maka dari itu Rumah Makan Darisa Cafe Campus diwajibkan untuk memperhatikan tempat parkir pengunjung dan memperluas lahan parkir.

\section{REFERENSI}

Daft, L., Richard. (2010). Era Baru Manajemen, Edisi 9. Jakarta: Salemba Empat.

David, Fred. R. (2006). Strategic Management: Consepts and Cases, 10th Ed.

Davis, Hofer. (2002) . Sistem Informasi Manajemen, Bagian I Pengantar Seri Manajemen. Jakarta: PT. Pustaka Binawan Persindo

Jauch., Lawrence R., and William F. Glueck. (1988). Manajemen Strategis dan Kebijakan

Perusahaan. Jakarta: Erlangga.

Kotler, Philip. (2001). Manajemen Pemasaran, Perencanaan Implementasi dan Kontrol. Jakarta: PT. Prehallindo.

Pearce II., John A., and Richard B. Robinson Jr. (2014). Manajemen Strategis Formulasi

Implementasi dan Pengendalian. Jakarta: Salemba Empat.

Rangkuti, Freddy. (2016). Teknik Membedah Kasus Bisnis Analisis SWOT. Jakarta: PT. Gramedia Pustaka Utama.

Supardi., Mastuti., Sri. (2003). Validasi Penggunaan Z-Score Atman. Jakarta: Kompak.

Sutojo., Siswanto., dan Kleisteuber. (2002). Strategi Manajemen Pemasaran. Jakarta: PT. Mulia Pustaka.

Tjiptono, Fandy. (2001). Strategi Pemasaran, Edisi Ketiga. Yogyakarta: CV. Andi Offset. 